The Geneva Papers on Risk and Insurance, 21 (No. 81, October 1996), 502-523

\title{
Gradual Retirement in the OECD Countries, a Summary of the Main Results
}

\author{
by Geneviève Reday-Mulvey* and Lei Delsen**
}

This article is divided into two sections: Section 1 examines the background to gradual retirement in relation to macro and micro issues and policies; against this background, section 2 assesses the potential for gradual retirement and makes recommandations for public and company policies. These sections, with modifications and updating, are taken from Parts 1 and 4 of the authors' book published earlier this year.

\section{The background to gradual retirement}

\subsection{Macro issues and policies}

This part will attempt a definition of the term gradual retirement and a brief examination of some of the concepts underlying it. Our main purpose, however, will be to focus on the following major factors: demographic and pension prospects, labour-market participation and the policy and practice of early retirement over almost the last two decades, new patterns of work and retirement, and finally recent public policies which reflect the emergence of new trends.

\subsubsection{Demography}

We shall not dwell here at any great length upon demographic factors since these are already very well-known. We would merely state in this context that they exercise crucially significant pressure on pension and health systems and on the labour market, and have most often been described in pessimistic terms. If things remain the way they are now, it is argued, the pressure demography exerts on our social security systems will become intolerable. The need to transfer an increasing amount of resources to the elderly, through pensions and health care, will have major consequences for the inter-generational distribution of income. As with many aspects of gradual retirement, the demographic situation differs

\footnotetext{
* Social economist and coordinator of the Geneva Association Four Pillars research programme on Work and Retirement.

**Assistant Professor at the Department of Applied Economics, Nijmegen University.
} 
significantly from country to country. Countries such as Germany, Japan and the Netherlands, which, in just 30 years, will have over one third of the population over the age of 60 will be subject to greater pressure than those with only $20 \%$ or $25 \%$ of over 60 s.

In fact, however, in many respects enhanced life expectancy is highly positive, for the potentially catastrophic arithmetic of demographic projection must be viewed in the context of the enhanced physical and mental health of the aging population many of whose members will be able, and will desire, to remain active much later in life. Japan, with a population that has aged earlier than that of any other OECD country, is a good illustration of this point. The median age of its workers rose significantly in the eighties without any apparent loss of productivity.

By the end of the century, a number of European countries and Japan are expected to show a decrease in the absolute number of working age people. Thereafter, projections indicate that a progressively larger number of countries will begin to experience shrinkage of the working age population, particularly during the second and third decades. This will affect state pensions and welfare programmes which are financed largely from taxes and social security contributions paid by the working population. But, at the same time, it will create more potential for extension of working life. With increased life expectancy a pension designed to cover ten or fifteen years of retirement might generate intolerable upward pressure on contribution rates were it to be maintained over 25 years, especially in countries like France where currently the average level of pensions is almost as high as the average wage. Indeed, contributions and rates of taxation cannot continue to rise without significant repercussions for wages, for the competitiveness of businesses, and hence for employment. In addition, all problems arising from population aging are aggravated by reduced economic growth. Lower growth rates make it more difficult to secure jobs and to finance social security programmes. The number of people employed, productivity per worker and trends in their real earnings will all be key elements in coping with expenditure increase.

\subsubsection{Pension provision}

The Geneva Association, in choosing a metaphor to describe pension provision, has likened the income security structure to an edifice resting on three pillars to which it has been proposed a fourth one be added. The first is the compulsory state or basic pension usually known as social security. The second is the supplementary employer or occupational pension. The third is income from personal pensions, life insurance, individual savings and assets. And the proposed fourth pillar, in a sense the 'raison d'être' of the present study, is the option open to older people to work part-time with a partial pension in order to supplement the income from the other three sources. Our concern at this point is with the first three pillars and their relation to the fourth.

In Europe, Japan and the United States, basic pensions are financed on a pay-as-yougo basis, either through social security contributions or from taxes, while occupational pensions are financed by funding (with the exception, for example, of France). Public pension spending in Europe is currently higher than in the USA and Japan. It is, however, set to rise considerably in Japan as well. As a percentage of GDP it ranges from 5\% in Japan to over $10 \%$ in most of the EU countries selected for this study. The combination of an 
aging population and a declining workforce is particularly alarming for public pensions. Under the assumption of constant rates of replacement (benefits as a percentage of labour earnings) and of labour force participation, public expenditure on pensions as a percentage of GDP would be expected to double across the OECD area between 1985 and 2040 (Holzmann, 1988). Since, for obvious economic reasons, this will be impossible to achieve, there will be a relative decrease of the size of the 1st pillar public pensions in most countries, and this is reflected in recent public pension reforms which have raised the pension age (or number of contribution years), and provided for a reduction over time in the relative level of pensions to wages.

Not all OECD countries have well-developed multi-pillar systems, since until recently, only the public pillar has been mandatory. Although the relative sizes of the mandatory and voluntary pillars - as measured by their relative shares of old people's income differ widely, public pay-as-you-go plans still represent high proportions of the elderly's income. However, as the World Bank's 1994 Report observes, occupational and personal pensions have grown fast and there is also a significant trend towards replacing pay-asyou-go systems by funding, so as to relieve the pressure on the active population which, as we have seen, is decreasing relative to the dependent one. This trend towards funding is expected to continue, since in countries with flat-rate basic pensions (such as the Netherlands and the UK), there is obviously more need for supplementary second pillar provision - and hence for funding - than in Germany or France where basic pensions are earnings-related. In some countries such as the UK and the USA, a proportion of the workforce (at least a third) is still not covered by any form of second pillar pension provision. This means that, in these countries, state pension provision will continue well into the next century to be crucial for at least this third of the population, and important for the average citizen. The first pillar pension will have to be maintained at a reasonable level, and where, as in the UK, policies have been introduced to reduce it, it will sooner or later have to be restored to an acceptable level, unless second pillar provision is made compulsory with enough government support to make it viable as far as the average wage-earner is concerned.

As to the third pillar, it is well-known that the rate of personal savings of most OECD economies is far too low for that pillar ever to be able, for the average citizen at least, to constitute a significant source of income during old age. That is why, for the standpoint of pension financing, in the medium and long-term, a flexible extension of working life is seen as highly advisable and for the less optimistic among us altogether unavoidable.

However, more crucial to the immediate issue of promoting gradual retirement are the portability of pension claims and the terms of pensions at end of career. Individual and defined-contribution pension claims are fully portable from one employer to another. Claims on the state pension are fully portable as well, because the schemes are nationwide. Defined-benefit plans operated at the firm or industry level have neither of these two characteristics, and are thus not fully portable. Limited portability hinders labour mobility, which is an impediment for forms of gradual retirement outside main employment. Moreover, if pension claims are not fully portable, because of long vesting periods, labour becomes less mobile. Arguments in favour of more funded systems are not only to diminish the inter-generational transfer, but also to improve economic performance. 
The final-salary, as opposed to average-salary, base upon which pension terms are frequently constructed in a number of countries (for example, the Netherlands, the USA and the UK) is a major obstacle to gradual retirement. An average-salary base of twenty years or more is gradual retirement neutral.

\subsubsection{Labour market participation and early retirement}

Over the last twenty years, in all industrialised countries, the employment situation has been characterised by an increasingly early exit from the labour market at end of career. While a continuous increase in life expectancy in good health and a steady extension of schooling for the young have been observed, employment has been entered into later and quitted earlier and, as a consequence, occupational life has shrunk considerably. In some countries such as France where the young enter employment especially late and the older worker leaves his or her job especially early, the average citizen now spends more time outside employment than within it!

A large number of OECD countries took special measures for older workers - nonwage income provision in the form of unemployment benefits, disability benefits and early retirement schemes - which have enabled older workers to withdraw from the labour market prior to being eligible for a public pension. These early retirement policies have resulted in decreasing rates of labour market participation which have been exceptionally marked in France and the Netherlands, very marked in Germany, relatively less so in the UK and the USA and least of all in Japan and Sweden. Of the active male population in the 55 to 59 age group in the first two of these countries, in 1993 less than $60 \%$ were in employment, while this rate was around $20 \%$ for those in the $60-64$ age group. At the other side of the spectrum, these rates for Sweden and Japan were respectively and approximately 80 and $50 \%$.

As a consequence, there has been a growing gap between the statutory age of retirement - which is 65 in the studied countries except Japan and France where it is 60 - and the effective age at which workers leave the labour market, voluntarily or not.

It is an established fact that the significant trend towards early retirement has been the result of a deep consensus - which we shall dub the 'old' consensus - part of a social contract between the State, enterprise, trade unions and the community. For the State, the main purpose of early retirement has been to reduce youth unemployment - which was high in the 1970s and 1980s - since in many schemes, at least until recently, there was a replacement condition. Moreover, it should be noted that, in most of the countries studied, the duration of unemployment benefit for older workers has lengthened, the latter not being required, prior to retirement, to register at labour offices. This has tended to result in an under estimation of unemployment. For enterprise, early retirement has had a twofold advantage - productivity can be enhanced through modernising the process of production and the firm restructured without the cost and the embarrassment of rising redundancies. For the trade unions, it has been a coveted prize in the long struggle to lower the retirement age and so leave workers, who so often started their working life young and frequently in strenuous jobs, some years of respite in good health. And last, the average citizen has greatly benefited from this trend particularly in countries where the financial terms of early retirement have been generous. 


\subsubsection{New patterns of employment and retirement}

There is no doubt that some of the main trends observed in employment over the last two decades constitute very favourable factors for gradual retirement. The development of services as a key factor of the modern economy has radically altered the existing work environment and in some respects created an entirely new one. If we consider not only tertiary-sector service activities per se but also service functions in manufacturing and agriculture (such as research, planning, marketing, maintenance, storage, quality control, safety measures, distribution), between 70 and $80 \%$ of jobs in our economies are now in services, and this trend is set to increase further in the years to come.

The very nature of service activities has brought into being a widening range of flexible job options. The rigidity that was so characteristic of the older manufacturing production chain contrasts starkly with the suppleness of the work patterns, flexible in both time and space, of our information age. There has, as a result, been an overall growth in the amount of work performed in part-time jobs, which, in some countries such as the Netherlands, the UK and Sweden, now constitute almost a third of jobs. Most of these part-time jobs are no longer of the old 'industrial' type (i.e. related to lower and frequently unprotected employment profiles) but increasingly involve the deployment of qualified experience which, for various reasons, people cannot or will not exercise in a full-time job.

Flexible work, a category which includes also self- and temporary employment, will become the norm in the professions and even in management over the next fifteen or

twenty years. For instance, millions of people will be working from home at some time during the week, achieving at least a $30 \%$ improvement in productivity and a considerable reduction in office and transport costs. Moreover in most countries, especially in the USA, Japan and the UK, the frequency of part-time and self-employment increases with age. Often self-employment assists individuals to remain economically active.

In most of the countries studied, employees in the services sector tend to retire later than those in the secondary sector. Statistics, both in the USA and in Europe, provide evidence that employees in manufacturing retire earlier than in the service sector (e.g. French Ministry of Labour, 1994). One reason for this trend is certainly that restructuring has so far been more radical in manufacturing industries and has led to stronger early retirement policies. Another important reason is that the content of work in most service activities is increasingly intellectual or mental. This crucial fact is supported by scientific studies which show that mental abilities decrease much more slowly with age than physical ones and that, as a result, productivity declines with age faster in manual work than in most whitecollar activities (Charness, 1985). That is why qualified employees tend to retire later than non-qualified ones, both productivity, and frequently motivation, remaining high much later in life.

\subsubsection{Gradual retirement}

In the past, most workers, whether peasants or craftsmen, used to retire gradually, i.e. in stages. With diminishing physical strength, they would work less and less. Gradual retirement of this kind was, as it were, a natural and progressive, sometimes imperceptible, downsizing of the workload and even today many self-employed people - doctors, archi- 
tects, lawyers, craftsmen and farmers - would, given the choice, not dream of retiring in any other way.

However, with the industrial revolution, work conditions had to be regulated and progressively the idea of retiring people when they grow old and less useful became established. Retirement came to be fixed at a certain age, earlier, obviously, for miners and others doing physically demanding jobs than for clerks. Almost everywhere, however, retirement was soon to be viewed as 'overnight' and irrevocable - 'la retraite couperet' or guillotine retirement, as the French were later to call it. Most people did not live for many years after retirement; a few years of rest, hopefully in good health, before death was all that could be expected. More recently, however, while the age of retirement has been lowered, so has life expectancy been increasing rapidly which means that, especially since the last World War, retirement has ceased to be a residue and has progressively become a period of life in its own right, a new stage and a fresh departure that can be planned and prepared for. And so, little by little, the idea of flexible retirement, of a transition period between a full-time career and full retirement, better suited to the needs of both the individual and the firm, has come into being.

Gradual retirement, often called phased, partial or part-time retirement, has been advocated, introduced and used for various reasons. By reducing work hours according to graduated and agreed schedules, it constitutes a way of avoiding the pension shock, following an abrupt transition from full-time work to full pensioning; it is also a way of achieving greater flexibility and individualisation of working life by distributing work and free time more evenly over the latter part of the occupational cycle, and a potential means of redistributing the available work supply. It further provides a 'soft' form of personnel reduction, a means of reducing growing exclusion of older employees from the labour force and, for management, cost-effective opportunities to retain people with valuable corporate knowledge and precious technical skills. Finally, actuarially, it reduces retirement and unemployment costs not only by reducing the relative volume of benefits but also by lengthening the contribution period and by increasing the contribution base (Delsen, 1990, Reday-Mulvey, 1993).

Many formulae for workload downsizing exist and the transition periods during which this occurs can run for anything from one to ten years. Approximately five years is the transition period most commonly encountered in the countries studied.

But gradual retirement, it should be understood, can mean a reduction or an extension of working life. In Sweden, where the retirement age has long been a relatively late one at 67 , gradual retirement was originally designed to facilitate a reduction in working life. In France, to mention another example, current public policies designed to reverse the early retirement trend use gradual retirement as a kind of part-time early retirement in substitution of full early retirement. The net effect of such policies, however, is to extend working life. The same may be said of Japan, as indeed of most of the countries studied. It is, in fact, our contention that gradual retirement constitutes a flexible extension of work life, and should be promoted as such. Often, at present, a bridge between the official and the effective retirement age, it is, we believe, destined to become the standard mode for extension of working life beyond any notional retirement age. It is precisely for this reason that the authors strongly advocate that there be no overall and absolute age limit to work and employment. 


\subsubsection{New public policies towards reversing the early-retirement trend}

Already in the early eighties, there were signs that the 'old' consensus on early retirement was not as solid as it had been; the State was becoming anxious about its cost. And although the change occurred at different times in different OECD countries - earlier in countries like France where it had started early and had been strongest or in Japan where there is an established tradition of working late - there was generally a rising awareness that the early retirement trend could not continue for ever.

In many countries apprehensions about intolerable future pressure on pension systems became particularly acute - as early as 1983 , the USA passed a law to raise the official retirement age. Most countries (Germany, Japan, France, Italy, the UK) have followed suit by increasing either the pension age or the number of contribution years to social security and by making conditions for retirees less favourable.

With regard to the specific issue of this study, public legislation has been passed in most countries allowing for a more flexible retirement, the possibility of combining a pension with earnings from employment and various possibilities for phased retirement, or what we call gradual retirement. During recent years, six EU member states have adopted measures for gradual retirement: Denmark (1988, but reinforced in 1995), France (1988), Germany (1989, effective from 1992), Italy, Luxembourg and Spain. The new member states, Sweden, Finland and Austria, adopted measures respectively in 1976, 1987 and 1993. Japan, for its part, adopted legislation in 1986, reinforced by measures in 1994 . The overall trend of these public reforms is clear: they enable mature workers to leave employment gradually and remain active later. The advantage of gradual retirement over other forms of policy (early retirement, unemployment or invalidity insurance) much used over the last two decades is, in our view, that gradual retirement can be built into retirement schemes and is thus more easily incorporated into overall employment policy, and can thus be considered a 'permanent' system.

For its part, enterprise is slowly becoming wise to the fact that jettisoning older employees sometimes incurs a net and irreparable loss of skills and corporate expertise. Early retirement is coming to be seen as a short-term or quick-fix solution to the problems of redundancies and of an aging active population, but also as a costly solution in terms of its increasing the rate of contribution for welfare. However, most corporate policies, thus far, are still greatly affected by the early retirement culture and difficult labour market conditions.

Many trade unions are becoming aware that the needs of the employee in the service economy are different from those of the worker in manufacturing, and that, with entrenched aging of the workforce, continuing training and adjusted work conditions are issues to be addressed. As to the older workers themselves, surveys show that they often desire some kind of transition between a full-time career and full retirement even if the vast majority still expect eventually to enter the latter at an earlier age and on very generous terms.

Therefore, a 'new' consensus appears to be emerging to replace the 'old', but the process of its formulation, by no means ubiquitous, varies from one country to the next. Although overall there has been a relative bottoming-out of the fall of employment rates 
for older workers, where not securely articulated into company policies, public policies have not yet necessarily produced the expected results. Raising the retirement age alone is, for example, decidedly no more than a partial answer to the problem.

\subsection{Micro issues and policies}

Not only will the aging of the work force in OECD countries result in a smaller body of workers with which to finance social welfare and public pensions, but the workforce itself as it ages will need to remain efficient and productive if it is not to jeopardise the competitiveness of our economies. Moreover, with the fall in new entrants to the labour market, it may well prove essential to keep older employees longer at work so as to avoid qualitative and quantitative bottlenecks in the provision of personnel.

In this part, micro issues and policies relating to gradual retirement are reviewed. An extensive literature exists on most of the areas involved, yet it is not in any way the purpose of this part to summarise them. We therefore indicate only those issues we believe most relevant to gradual retirement: work performance, age discrimination, personnel management, training, the wage-cost profile, part-time and flexible work, employee preferences and the life-cycle of the worker.

\subsubsection{Work performance}

The whole notion of capacity for work, i.e. for productive activity, is changing dramatically. To cite but one rather obvious example, today somebody who in traditional industrial society suffered from severe disadvantage through physical handicap can now become a perfectly competent computer programmer, whereas the athlete, in spite of the traditional advantage of exceptional physical fitness, will remain computer illiterate unless he or she take steps to remedy that deficiency. Education, health status, experience and psychological attitude, then, are combining in new ways to engender new notions of capacity for work.

Scientific research seems to be moving in new directions also, causing long-held prejudices to change. The evidence of biological studies now points to the possibility of regeneration of neurons and brain cells. It is now well established that mental abilities decrease much slower and later than physical ones and can, especially with training, remain viable much after 60 or even 65 years. It is becoming obvious also that work, especially when part-time and in moderation, has a positive effect on the health of people after 60 years.

There exists a great number of studies on this issue and it is here only possible to touch upon one or two examples. According to surveys in the United States (Commonwealth, 1991), and contrary to conventional corporate opinion, the general perception of older workers is positive: lower turnover, more conscientious, possessed of better judgment and more flexible. There is strong evidence that older workers are more flexible in their attitudes to work assignments and conditions than younger ones. Indeed it is thought that because they possess long experience, they can perform multiple tasks and, as the Japanese experience will show, frequently welcome mobility. Having often benefited from good material conditions during most of their career and with career prospects behind them, they are more ready to accept conditions which would not be acceptable to younger colleagues who have future promotion in mind. A British survey (Warr, 1994) on 
the topic shows that the performance of older workers surpasses that of younger ones on six accounts: they are reliable, work hard, are effective in their job, think before they act, possess interpersonal skills and work well in teams. On the other hand they fare less well than younger workers in four areas: the ability to grasp new ideas, adaptability to change, acceptance of new technology and the ability to learn quickly. In France, according to the survey made for the French chapter in this study, it appears that in many firms the greater flexibility of older workers is perceived as something which in years to come should favour an extension of working life.

There are many work activities in which age is a definite advantage or, at least, neutral (Warr, 1994). American firms which have made wide use older workers and retirees are as a rule entirely satisfied with them (Libassi, 1988). The same appears to be true of Japanese firms, especially the smaller ones, where the long experience of older workers and their ability to perform multiple tasks are highly appreciated. In the UK, such firms as make use of older workers state that they do so for sound commercial reasons: older employees, it is found, establish contacts with aging customers more easily. In many firms, for instance in Japan, qualified employees are working as part-time consultants in the firm they used to work for or in an affiliate.

\subsubsection{Age discrimination}

There is abundant literature in this area also. One of the most complete studies (Eurolinkage, 1993) revealed that there is substantial discrimination, either direct or indirect, at various stages during the end of career and that it takes, among others, the following forms: early exclusion from the workforce, for older unemployed re-entry to the market is virtually impossible, lack of training opportunities and discrimination at retirement age. Discrimination against older workers takes the form of differential treatment based upon prejudices or stereotypes. These include the view that older workers are more expensive, less productive and less adaptable than younger ones. Such prejudices may be held by employers, the public, policy-makers and even by older workers themselves. Sometimes these views reflect real facts, which is why it is crucial to modify wage costs and increase adaptation, for example, through training. Gradual retirement, because it involves parttime work in some shape or form, has been viable particularly in firms where the latter is established or common practice. Part-time work seems to have a number of advantages: it often increases productivity, reduces absenteeism, and enables the firm to retain 'within its walls' the older worker's corporate knowledge and experience while allowing for a reduction of costs and promotion of younger employees.

Age discrimination legislation is the focus of much debate currently and doubtless specific and/or general measures will be forthcoming in the not too distant future. For the time being, however, only the USA (with Spain) has adopted significant measures to protect older workers' rights in employment and reduce blatant forms of discrimination. But, such legislation has not brought about any general improvement in employment opportunities for older workers. This shows to what extent age discrimination is part of the early retirement culture dominant in the USA and in most OECD countries. In countries like Japan and Sweden, by contrast, where different cultures obtain, there is much less discrimination. 


\subsubsection{Personnel Management}

While until a few years ago personnel management had concentrated mostly on employees between the age of entry to the firm and 40 or 45 years, with the aging of the work force there are signs of a new awareness of age-specific problems within firms and this is beginning to influence the design of human resources management strategies. The sort of end of career problems that tend to crop up around 55 years should in the normal course of events have been foreseen and catered for several years previously. For it is when the employee reaches around 45 that questions about the future role he or she is going to play within the enterprise or outside should begin to be asked. Therefore the new 'prospective' staff age-management techniques are not designed to produce job security per se but rather the added human-resource value of constantly updated skills buttressed by experience. The Skills and Aptitudes Review and the Training Plan are two of the main instruments employed in 'prospective' management (Entreprise et Progres, 1993). The Skills and Aptitudes Review provides a full description of the employee's professional capacities and his future potential, the overall aim being to draw up a personal end-ofcareer plan which, while fully meeting the needs of an enterprise, enables the employee to shape his/her professional future and where necessary acquire any additional training he/she may require to suit his/her or the firm's needs. According to several of the country authors, firms are starting to adopt this approach and not only the big firms which can more easily afford the costs involved but also some of the smaller, more dynamic ones.

In some cases it has been found that certain functions are better suited to end-ofcareer employees and these are being developed in some of the firms surveyed for this study: trainers, tutors, in-house and outside consultants, negotiators. Some firms are starting to adjust structure and practices so as to be able to take full advantage of their older employees. Meanwhile experiments have been conducted on manual workers, for example in France at Renault and Aérospatiale, to introduce modern ergonomic techniques into the workplace and to deploy workers in a differentiated and positive fashion until retirement age.

Personnel age-management also includes managing new kinds of flexibility, reduced time schedules, and working from home part of the week, etc. None of these flexible options is without special problems and yet, once the initial steps have been taken, they often prove to be a source of savings for the employer and of considerable satisfaction for both parties.

\subsubsection{Wage costs}

Traditionally, older workers have been more expensive because of the seniority rule which has existed in most firms worldwide. Young workers have in fact been subsidising the higher wages of older workers. In principle, there is nothing wrong with this rule; it has led to the life-employment we have known for decades in large corporations and in the public sector. However, it causes problems when the average age of the workforce increases and when workers approach the end of career. To the extent that older workers are paid more than their effective productivity, enterprise will have an incentive to get rid of them or, when redundancy occurs, to shed them first. That is the reason why the seniority rule has thus far been, and will remain until abandoned, an obstacle to gradual retire- 
ment or to any extension of working life. Moreover, in a few countries, pension rules cause pension contributions to increase with age.

However, there have been profound changes over recent years in adapting pay profiles to performance, first in American and British firms and subsequently, although to a lesser extent, among German, Dutch, French and even Japanese firms.

The new performance-based remuneration, especially for professional categories, will promote a different wage curve and should thus make the older employee more competitive.

It is, at all events, now known that productivity per hour in many work functions increases when a worker moves from full- to part-time. Moreover, experience of part-time work and partial retirement in Swedish firms has shown that part-time work tends to reduce absenteeism which is generally rather high for full-time older workers.

The experience of Japanese and American firms in some sectors has been to retain older workers or re-employ retirees, often on a part-time basis, but performing different tasks, less demanding than the ones they did previously, and therefore to pay them considerably less. This practice should not necessarily be encouraged. It is, however, a fact that older workers, especially those drawing a pension or a partial pension, have smaller financial needs. Nevertheless, with continuing training, skilled workers remain productive late in life, especially when working part-time, and could well continue to be active in their field and to be paid according to their performance.

As far as pensions are concerned, rules which make them more expensive for older employees should be modified and should at very least be rendered gradual-retirement or extension-of-working-life neutral.

\subsubsection{Training}

The globalisation of economies will imply that a country's competitiveness largely depends on the quality of its supply side. Investment in human capital becomes a condition sine qua non for future competitiveness. Employment adjustments that are too rapid and rely on the external labour market to a large extent, as in the USA, may not prove as satisfactory in the long run as slower transaction-cost 'employment retention' model prevalent in Japan. What appears to be increasingly important is the functional flexibility which the new technologies have made necessary. The modern enterprise requires the deployment of higher level skills and performance of a much broader mix of tasks/functions than did the traditional firm.

By extending training opportunities, making employees more effective in their current firms but also more employable in other firms, and by easing thereby the consequences of job loss, the stage can be set for more flexible and hence more productive employment systems.

However what appears to be crucial for gradual retirement is for enterprises to extend training or retraining opportunities until end of career and not to reduce them from the age of 40 or 45 onwards, as has hitherto generally been the case. In many firms early retirement has escalated the demotivation of workers already in their early 50 s who see no 
sense in continuing training since their career prospects are very short. Any form of extension of working life, therefore, has a positive psychological effect on workers who have a reason to invest efforts as well on management which sees training as a longer investment. Greater psychological content will have to be given to training if is to help older workers to remain mobile, motivated and adaptable. Continuing training now has be be adapted to suit the older worker, whose learning and pedagogical needs are known to be different from those of younger cohorts. Training of older workers, then, must be designed to take full advantage of their experience and knowledge in introducing to them new ways of thinking, doing, or being.

Moreover early retirement policies, it should be noted, have had negative consequences for firms because of the loss of experienced workers who have a capacity for training younger employees and who in general have more to contribute to enterprise culture. Many firms in the USA, France and the UK have recognised these facts and are now beginning to reverse the trend. Older qualified workers have indeed an important role to play in the training of younger employees whether it is in formal teaching courses or simply by working in teams. It is also becoming quite common to see qualified engineers, economists and insurance experts pursue a second career as teachers in their field of knowledge and work experience.

\subsubsection{Part-time and flexible work}

The development of part-time employment which has been rapid over the last two decades has, as it were, prepared the ground for gradual retirement and greatly enhanced its potential for the years to come. In countries where rather traditional attitudes to parttime work have for long existed, such as Germany, France and Japan, employers' attitudes have started to change and the need for flexible work patterns has at least been recognised. Employers' objections to part-time work, job sharing or gradual retirement are invariably the same: a job cannot be 'split', organisational problems, failures to communicate, decreased work commitment, poorer output. However, where part-time work has been developed or job sharing used, supervisors generally welcome it. Where it has not been experienced, people tend to be skeptical (Delsen, 1995). Practice shows that many more functions could be performed by part-timers than is currently the case, that even jobs hitherto considered to be totally 'unsplittable' e.g. management functions can in fact be viably divided.

Experience in Europe with gradual retirement thus far shows that where managers view part-time work positively, reduction of the work time has caused few problems, once the initial organisational and adaptation stage is passed. Against the extra administrative, planning and sometimes equipment costs, must be set reduction in absenteeism, higher flexibility, improved morale and raised productivity. The benefits gained from retaining the skills of older workers outweigh their costs, and this will be especially the case when the supply of new entrants to the workforce diminish. Where a job can be shared between a younger and an older worker, not only will the employer be able to retain the human resource capital of the older worker but the system may also provide - as practice in French firms shows - a cost-effective way of imparting a specific skill endowment to young workers. 
Both working conditions and pension provision should be sufficiently flexible to enable the transition from work to retirement to take place smoothly. But, in principle, there are structurally no business or economic obstacles to the introduction of gradual retirement (Hart 1984, Delsen 1995). The latter could also a useful praxis for developing parttime and flexible work patterns in enterprise and could, finally, prove an ideal way of lengthening working life.

\subsubsection{Employee preferences and the life-cycle}

The rigid, linear, three-phase life cycle - youth and training, adult life and work, withdrawal from work and retirement - that has predominated throughout the period of the mature industrial revolution is today gradually being replaced by a cycle which is less certain, less predictable and of necessity more creative. Among other things it is characterised by more flexible work patterns, more training throughout professional life, periods of unemployment and sabbatical leave, and more active retirement. Gradual retirement is therefore very much part of this new approach to the life cycle.

Workers who have retired over the last twenty years had usually begun what proved a long and arduous working life at an early age. They have been part of the long pattern of economic growth and, while largely benefiting from exceptional material well-being, they have often had little time to devote to activities outside the work place. Retirement comes, then, as a well-deserved rest, a kind of golden period with time to enjoy the leisure a good pension makes possible. However, many surveys have already revealed that overnight or 'couperet' retirement has proved a difficult experience for many retirees who have not had time to adjust before entering it. Many have switched from a position of social prestige within their company into what has been called 'social oblivion' (Guillemard, 1990). If only for this reason, a fair proportion of retirees wish to remain mentally alert and socially integrated.

People retiring in 2000 and beyond will, for the most part, have enjoyed much longer periods of education and training. Their working life will have often been interrupted by unemployment or part-time employment, for a few, by sabbatical leave. On the whole, most of them will have experienced much more flexible work patterns than their parents' generation. Indeed, new categories of employee nowadays - other than mothers of young children or young people in training - are concerned to organise their work in new ways and frequently quite simply to work less. These new categories include workers in the midlife period who wish to combine regular work with meeting other requirements (e.g. selfemployment, a return to training, community service of one sort or another, caring for elderly parents, etc), and workers at the end of their career who wish gradually to move from a full-time working life into healthy retirement. Since their youth, this generation has had much more leisure time and a majority has had continuing training in service or outside the firm. Often they have had two or three different careers (Gaullier, 1992).

When these workers, the baby-boomers, are questioned about their wishes with regard to retirement, many - particularly if they are qualified and sense that they are making a valid contribution - would wish to keep a foot in the occupational door for some years after the legal retirement age. As was so aptly observed, the relative utility of leisure and retirement to that of work will tend to diminish in the years to come (Kessler, 1990). 
However, a majority of baby-boomers will wish to alter their work rhythm and will therefore be attracted by part-time work as part of a gradual withdrawal from full-time employment. Recent European surveys (Eurobarometer, 1993) confirm that most people are in favour of flexible retirement, and American surveys have shown that, for men, the desire to work part-time increases with age.

\section{Potential for gradual retirement and recommendations}

The situation in the countries selected for study (Sweden, France, Germany, UK, Netherlands, Japan and the USA) shows that extension of working life is seen everywhere as a crucial policy for reducing the burden of social expenditure in years to come. Because of its flexible nature which is well suited to end of career, gradual retirement is finding increasing favour with the majority of workers, and growing acceptance with management and trade unions. There are, of course, features common to all the countries studied. And yet the situation as observed in 1995 varies greatly from one country to another. In this part of our article, we shall:

1) assess the extent of, and potential for, gradual retirement in the countries considered, by classifying them in four categories;

2) make recommendations for both public and company policies, and stress the need for their better integration; and finally

3) say a few words about the now evident need for rethinking the issues of work and retirement as part of a new approach to welfare in our societies.

\subsection{The situation in the countries studied}

In order better to understand the main trends and features of the current situation in the countries studied and therefore the potential of each for gradual retirement, we propose a tentative typology of four models: the Swedish, Japanese, Continental and AngloSaxon models.

The Swedish model which has worked successfully for almost 20 years. In that country, labour force participation rates have decreased less than elsewhere and, in, in spite of the severe recession, for men in the $60-64$ age group they were still at over $56 \%$ and at $82 \%$ for the $55-59$ age-group. Almost $40 \%$ of workers between 60 and 65 are in some form of gradual retirement, on generous financial and professional terms.

There are three main reasons why this model has been successful: availability of parttime jobs and the habit of working flexibly, a good partnership between the State and enterprise, and the high replacement rate of partial pension arrangements. In Sweden, although no direct legislation on the issue exists, there is little age discrimination compared to countries such as the UK, France or Germany. And it can be said that a culture of late and phased retirement has already been established there, even if the events of the recent past might seem to suggest otherwise. Firms, especially big ones, make impressive use of continuing training until end of career and the recent thrust of employer policy has been to strengthen the relation between productivity and wages.

The fairly widespread practice of gradual retirement in Sweden has been made possible above all by legislation which dates back to 1976 and which has provided for the com- 
bination of a partial pension and part-time work with good replacement rates. Whenever, as in the past, the Government has tried to cut expenditure and reduce those replacement rates, there has been an almost immediate decrease in the use of gradual retirement.

Important reforms to the pension system were introduced in June 1994. These will raise the age of partial retirement from 60 to 61 and reduce the partial-pension replacement rate. Moreover pensions will be based on life-time earnings, furnishing an incentive to work longer. However, the flexible partial pension/part-time work option, being deemed too costly, is due to disappear in 2000 , leaving, as the main option available, a partial early old-age pension scheme which is less attractive financially.

The potential for gradual retirement in Sweden is now not as great as in the other countries studied, for the simple reason that so much has been achieved already. What now appears important is to be able to follow along the narrow path of public savings so necessary to the country's economic well-being while, at the same time, conserving its practice of gradual retirement and the other social-economic policies that have made it in recent decades a model for so many other countries.

The Japanese model has in common with Sweden high participation rates for older workers. It is well-known that this is due in part to the 'shokko' system of employment normally operated by big firms. Under this system, large numbers of employees work on after the pension age of 60 , frequently up to 65 if not later, and mostly part-time, often in a subsidiary of their previous employer. The financial and professional conditions offered to workers are not as generous as previously, but their income from this work is additional to the pension which for some of them is still too low. Self-employment is also developed in Japan among older workers, and there exist 'silver centres' where workers, usually coming from smaller firms, can obtain information and support in finding part-time employment after the pension age.

It is common knowledge that Japanese workers value the social "inclusion" that this type of employment after pension age confers. Various surveys show that Japanese workers would like to continue even later than is nowadays possible.

The seniority rule which used to be very strong in Japan has been made more flexible, and now 50 is becoming the age as of which there is no further increase in the basic wage; sometimes there is even a decrease. I. Shimowada points to the trend towards 'more flexible management policies' which 'will help to rectify the imbalance between performance and wages which is thought to constitute a major obstacle to more widespread employment of older workers'. More training, more flexible work and more job redesign are being offered, it appears, by an increasing proportion of firms.

The reforms of 1986 and 1994 have been highly instrumental in promoting employment of older workers. They have made early retirement less attractive, have modified the earnings tests, have made the future state pension obtainable in full only at the age of 65 instead of 60 (this change will come into force between 2001 and 2013), and have provided various subsidies to companies wishing to employ workers after the age of 60 . There can be said to exist in Japan a government-led global policy and strong incentives from the State to encourage enterprise to extend work-life in a land whose life expectancy in good health is one of the highest in the world. Japan's labour force, it should be repeated, is aging earlier 
than those of Europe or America and, it seems, with no loss of productivity. However, although practice of gradual retirement outside main employment is already widespread, the potential for more gradual retirement is considerable since Japan's goal in this matter is to go from 'a society which retires at 60 to one that works until 65 '. This will require extending and reinforcing many of the measures that have already been set in place.

The Continental approach is exemplified by France, Germany and the Netherlands. These three countries are characterised by a practice of very early retirement which has been encouraged over the last fifteen years by public policies, and by a strong consensus between enterprise, the State and workers, resulting in very low activity rates for workers from the age of 55 . It has been said, and rightly we believe, that labour force participation rates in these countries reflect more the availability of generous social-security provision than the situation of labour markets. In all three countries a strong early retirement culture exists. Over recent years, disability, unemployment and early retirement routes have been reduced significantly but they will have to be made even less accessible and more expensive in the future. In Germany and the Netherlands, for example, 'invalidity and disability pension routes have been, and remain, loopholes for those who want to retire' (W. Schmähl et al.).

Public policies and collective agreements to encourage flexibility and phasing have been launched in these countries, for the time being more so perhaps in France than in Germany and the Netherlands. And there are the beginnings of a trend away from early retirement, especially in France and the Netherlands. In France over 50,000 workers were on gradual retirement at end of 1995 and a fair number of examples of satisfactory practice already exist in this area (Rhône-Poulenc, Aérospatiale, Crédit Agricole, UAP, AXA, Hewlett-Packard, etc); they show how important financial help from the State and a good partnership with enterprise really are. The task, however, of convincing workers who have gotten used to the idea of very early retirement of the virtues of extending work-life is not an easy one.

In Germany, recent legislation (Pension Reform Act of 1992) provides the basis for gradual retirement-oriented policies, but for the time being implementation has had only a very limited impact due to labour-market difficulties (German reunification) and to the lack of sufficiently strong and flexible financial incentives (for example, the age at which phased retirement becomes possible is too late). Important measures to reduce exit routes in order to create more incentives to later and phased retirement were announced by the Government in February 1996, and over recent months labour unions have also been proposing measures to promote gradual retirement.

In the Netherlands, collective agreements have recently been concluded (ex. the Philips agreement in Spring 1996) and reflect the growing trend away from early towards gradual retirement. Flexible work patterns are widespread which is, of course, one of the important conditions for gradual retirement, and, since 1994, part-timers may no longer be excluded from pension provision. A major obstacle to any real progress, however, is the fact that the majority of pension funds remain final-salary based, but the Government and social partners now appear to favour a move towards average-pay systems. Other necessary company measures are, as in Germany and France, more training for older workers and more flexible pay systems. 
In all three countries the potential for gradual retirement is considerable, and we shall be indicating below what we believe is required to make it a large-scale reality.

The Anglo-saxon approach is exemplified by the UK and USA, where no strong public policies exist, but where flexibility is common. In both these countries part-time work and self-employment among older workers have been increasing.

In the USA, due to the downsizing of firms and to the collapse of the so-called 'career employment system' for older workers, many employees in their fifties have been losing their jobs (Doeringer, 1993). Between the ages of 55 and, all too rarely in practice, 65 when they can begin drawing their state pension, they have had to take 'bridge jobs' which are often part-time, frequently pay less, and almost always provide lower levels of protection than their previous employment. And yet, well-known cases of post retirement-age employment exist such as, for example, the Travelers where working conditions for 'retirees' are usually excellent (H. Sheppard in his chapter \& Libassi, 1988). Other examples can be found in banks, insurance companies, town administrations, colleges and supermarkets but the conditions in such cases are not always representative of average conditions. In one sense, gradual retirement can be said to exist to a certain extent in practice, often outside main career employment, but legal measures will need to be taken in order to create the proper statutory social and financial framework required for its propagation. Recent surveys show that the potential for further gradual retirement is still considerable.

In the UK, public early-retirement policies were tightened up at the end of the 1980s due to financial constraints and, since then, official policy has consisted of attempts to convince large employers of the advantages of retaining older workers much later than they, the employers, would wish to do. Employers' practice produces some interesting examples of better management of older workers. But in the absence of proper legislation and sound financial incentives, the results of this policy have not been very encouraging. Existing pension rules are once again an obstacle, based as they so often are on final salary, and funded from contributions which increase with the age of the employee.

\subsection{Recommendations for public and company policies}

\subsubsection{Public policies}

Raising the retirement age or changing pension conditions and rules will not, of themselves, suffice to reverse the significant trend towards early retirement which has taken place over the last twenty years. Reference has been made, more especially, to a much-needed change in attitude since all countries have been deeply affected by the socalled 'early retirement culture', particularly the three continental countries and, to a lesser extent, the UK and the USA.

All the countries examined have now initiated moves towards pension reform. Yet what stands out as essential is that public policies need to be sufficiently comprehensive and accompanied by incentives at various levels if a significant change of direction is to be hoped for in the years to come. Those countries which so far have been more successful in implementing gradual retirement are probably the ones which have designed global public policies (Sweden and Japan, and very recently France). 
First, it is essential to make early retirement options as well as disability and unemployment routes more difficult, more costly and their terms more stringent. Although the countries studied, especially the Netherlands, Germany, Sweden and France have all, in varying degrees, moved in that direction, much ground still remains to be covered. It will be objected that current labour market conditions, and especially high rates of unemployment, make any progress in the desired direction at this time very difficult. It is precisely for this reason that gradual retirement, we believe, cannot be handled outside the broader context of employment redesign and redistribution.

A second set of policies has to do with gradual retirement itself. The USA and the UK do not as yet have any specific legislation in this field, and the American authors, at least, have called for some kind of statutory structure for social security within which to promote gradual retirement. In the USA, for example, earnings test rules have been described as too severe. Political change in the UK would almost certainly bring with it welcome legislation in this area.

In other countries recent legislation (or, in the Netherlands, collective agreements) is beginning to promote replacement of full early retirement by gradual early retirement. But such legislation clearly needs to be accompanied by financial incentives from the State, and we can see the positive results of policy strategies allied with incentive measures in countries like Sweden, Japan and more recently France. The German authors indicate that one of the reasons why thusfar implementation of new legislation has not been effective is because of insufficient financial incentives and of regulations that are too complicated. The age at which gradual retirement can commence is also crucially important. Changing the deeply-rooted mindsets of the early retirement culture requires drastic redesign and gradual implementation. Japan seems, in this respect, to be a very good example of how to do it.

Financial incentives can also help employers hire older unemployed workers, and this measure exists in at least two countries, France and, since July 1995, Sweden. They can help target older workers for continuing training until end of career. But in the final analysis it appears that a good partnership between the State and enterprise is vital to the development of gradual retirement.

\subsubsection{Company policies}

In this domain, as for public policies, the country chapters of our book describe a number of changes over recent years. However, all too frequently, new management policies for older workers have concerned too few firms and therefore too few workers. All country chapters have referred to model firms and instances of good practice. These experiences need in future to become the norm. Among the many company measures whose promotion country authors have recommended, we can examine here only the most important: personnel age-specific management, occupational pensions, training, pay policy, and part-time and flexible work options.

\section{Personnel Management}

For the time being, it is probably more awareness of future challenges that is developing in representative firms in the countries surveyed than new age-specific management 
practice. Whatever the case, it is a fact that in all countries a small number of dynamic firms, often big ones, have started new policies either for employees in mid-career (such as abilities assessment and the drawing up of training plans for workers aged 40 to 45) or for their better integration at end of career. Mid-career abilities and aptitudes assessments, the training plan, internal or external mobility, ergonomic methods, flexible work schedules or reduced workload at end of career (and sometimes earlier), are some of the instruments being used and there is no doubt that they will be developing over the next few years.

The justification for new age-specific policies must always be commercial and economic before it is social. Older workers, it has often been recognised, perform tasks better or differently than younger ones, and the 'differently' can be an advantage where, for example, customer relations, sheer expertise or team-work are involved. The best way to convince other firms or other departments within a firm of the validity of a new approach to workforce aging is to show them the results of new practice.

If policies for enhancing the employment opportunities of older workers are to make any headway at all, they will need to serve as much the interests of employers as of employees. Ideas, therefore, for improving the various variables which can make employment at end-of-career less expensive, more flexible, more adaptable and equally productive, have to be marshalled and built into corporate practice. Examples of good practice will be imitated and as a result new norms established as has, to some extent, already happened in Sweden and Japan.

\section{Occupational pensions.}

In some countries these currently constitute an obstacle to gradual retirement and in various ways. First, many Dutch, British and American pension funds are final-salary based and authors have called for changes to the rules to make them average-earnings based. In the UK, in addition, contributions from employers increase with age; this is another rule that will need to be modified. In the countries studied, there seems to be an emerging consensus about the need to make such changes, and it has also been suggested that there is a need to align the payment rules of occupational pensions on those of the statutory pension schemes for a more favourable impact on gradual retirement. And finally, for Germany, the UK and the USA, it is recommended that the rules for occupational pensions should cease to be such a strong incitement to very early retirement.

\section{Training}

In order for older workers to remain motivated and productive, continuing training should not terminate at 45 or 50 years but should continue until end of career. Countries where such company policies exist are in a much stronger position when the decision to extend working life is taken, although all countries need to develop such policies further. The statistics for Sweden show how impressive training is even for older workers. In French bigger companies, the same policy is beginning to be encountered. In Japan, there are incentives for training older workers, and bigger firms are running successful schemes to meet this need. In the Netherlands and Germany, training until end of career has also developed over recent years but much more needs to be done. The situation appears less 
encouraging in the USA and the UK, and will require more incentives more carefully targeted, from the authorities, and more challenging strategies from firms if things are to be improved.

\section{Pay Policy}

Another important variable is pay policy. It is perfectly clear from most chapters that seniority-based policies, by raising the wage costs of workers at end of career, constitute a real obstacle to all forms of extension of working life. In all countries, there is a growing trend in wage calculation today towards reducing the weight of the seniority factor and increasing that of performance. This trend is perhaps more prevalent in the United States and the UK, but is now to be found in France as well where, in some sectors such as insurance, the old seniority pay system has been recently scrapped. In Japan, where seniority is a revered social value, seniority calculation now frequently levels off at 50 , work after the age of 60 being outside main and regular employment, with very different wage profiles. In Germany, Sweden and the Netherlands, employer policy has been to strengthen the relation between wages and productivity.

\section{Part-time and flexible work}

The development of part-time and flexible forms of employment is obviously important for gradual retirement. Most countries have seen such development at either end of the life-cycle. Countries such as the Netherlands and the UK have a high rate of parttimers. Some have improved legislation in this respect so as to provide better levels of protection for part-time work (for example, France and the Netherlands). In other countries, there is availability of part-time jobs for older workers either inside (e.g. Sweden) or outside main career employment (e.g. Japan, USA, UK), but social protection for part-time employment has to be improved in the latter cases. It has been recognised by many that part-time work is likely to improve the productivity of older workers, reduce absenteeism and increase motivation. Examples of good initiatives for promoting part-time work in a targeted fashion are Japan's 'silver centres' or the part-time jobs banks such as ABLE or NOWIS in the USA.

\subsubsection{Rethinking work and retirement, or the need to coordinate employment and social policies}

At the end of his chapter on the USA, Harold Sheppard asks:

"Is it possible due to the challenges stemming from chronic unemployment and to the potential of technology-driven productivity increases, that we are on the verge of a redefinition of what constitutes full-time - to a point where something that is now considered part-time will be categorised as full time? Such a policy, among others, could be salutary to the challenges of system-wide joblessness."

It is very much the authors' conviction that demographic and financial pressures require that the welfare state define new social and employment policies. Advances in information technology make it imperative for our societies carefully to reexamine the concept of 'full' employment. While, over the last 25 years, the services sector has unquestionably proved prolific as a creator of jobs, current and foreseeable restructuring in cer- 
tain branches of the service sector - for example, banks and insurance - is going to result in job losses which will not necessarily be offset by job-creation in other branches, to say nothing of further substantial job-losses in the years to come in industry and agriculture. Moreover, in spite of a reduction in the number of young persons entering the labour market, increased productivity and labour substitution by capital will oblige us sooner or later to face the issue of how much work the average citizen will need, or can expect, to do.

Given the overall volume and new quality of work the service functions offer, new employment policies could be devised around the notions of basic employment. This might mean a shift from 'full-time' employment and exclusion from the labour market of over $30 \%$ of potential workers (those receiving social benefits in one form or another, that is the unemployed, early retirees, older people wishing to remain active after the retirement age, young students, mothers with family responsibilities, etc) to a society where governments and firms are concerned with assuring basic employment for all, that is, part-time work for all citizens of an age and ability to work. This new profile for 'full employment' would be positive for both enterprise (higher productivity, less absenteeism) and the community (less exclusion, more time for community activities) (Reday-Mulvey, 1993). Much less financial support would be needed for the unemployed, the student, the mother, the early retiree and so forth. With such an approach it might be possible to build a society where the average citizen, whether young or old, man or woman, would work at least 1,000 hours per year, more if he or she is able to find extra-hours of work, and be integrated socially with free time for other activities, whether economic, social, cultural or artistic. It has actually been calculated that in France the average number of hours worked per year divided by the potentially active population (people from the age of 20 to the age of 65) is around that number. This new full-employment concept is based on the complementarity of equality and efficiency (Lei Delsen, 1995). It constitutes an essential facet of what could be called 'a new welfare deal'.

Social and employment policies, in other words, need to be combined or, at the very least, coordinated if we wish in future to promote a society less divided between two extremes: those who work too much and those who are excluded from productive activity of any sort (Chen, 1995).

Therefore, gradual retirement seems to stand at the crossroad of two important issues:

- the need to extend working life for very sound reasons which have to do with the financing of pensions and the proper management of human resources and skills; and

- the need to develop well-protected and regular part-time work not only as a transition from full employment to full retirement, but also as a bridge towards a morally proper division of "full" employment whose redefinition is now long over-due. 


\section{REFERENCES}

Charness, N. (1985). Studies in Human Performance, John Wildey and Sons.

Chen Y-P.(1995). Partial Pensions for Partial Retirements: Need for Coordinating Social Security Policy with employment Policy. Paper presented at the Mini-White House Conference on Aging, Baltimore, National Council of Senior Citizens, 23-25 February.

Commission of the European Communities (1993), Older People in Europe: Social and Economic Policies, The 1993 Report of the European Community Observatory, Brussels: DGV.

The Commonwealth Fund (1991). New Findings show why employing workers over 50 makes good financial sense for companies, New-York.

Delsen, L. (1995). Atypical Employment: an International Perspective, Causes, Consequences and Policy, Wolters-Noordhoff, Groningen bv, Netherlands.

Delsen, L. and Reday-Mulvey G (1996). Gradual Retirement in the OECD Countries, Aldershot (UK): Dartmouth Publishers.

Eurolinkage (1993). Age Discrimination against Older Workers in the European Community, E. Drury, London.

Entreprise et Progrès (1993). La gestion des fins de carrière - La préretraite n'est pas un acquis social. Paris.

Gaullier X. (1992). The Changing Ages of Man, The Geneva Papers on Risk and Insurance, No 62, (Janvier), pp. 3-25.

Guillemard, A-M. (1990). Les nouvelles frontières entre travail et retraite en France, La Revue de l'IRES, No 2 (Hiver), pp. 41-98. Paris.

Kessler D. (1990), Les Quatre Piliers de la Retraite, Etudes et Dossiers, No 144, Mars. Geneva: The International Association for the Study of Insurance Economics.

Ministère du Travail, de l'Emploi et de la Formation Professionnelle (Ed) (1994). Emploi et Vieillissement. Paris: La Documentation Française.

Reday-Mulvey, G. (1993). Facing Social Uncertainty: Towards a New Social Policy, in Giarini, O. and Stahel, W. Limits to Certainty, Dortrecht: Kluwer Academic Publishers.

Warr P. (1994). Research into the Work Performance of Older Employees, The Geneva Papers on Risk and Insurance, No 73, October, pp. 472-480. 